\title{
¿LA IMPORTACIÓN DE UN MODELO FRANCÉS? ACERCA DE ALGUNAS REFORMAS DE LA ADMINISTRACIÓN ESPAÑOLA A PRINCIPIOS DEL SIGLO XVIII
}

\author{
ANNE DUBET \\ Université Blaise Pascal/CHEC, Clermont-Ferrand*
}

«Conviene notar que todas las desórdenes de este país existían en Francia durante la minoría del Rey. Basta con respetar sus ordenanzas y reglamentos desde aquellos tiempos, con esta diferencia: si alguno de ellos no conviene a los usos de este país, no conviene introducirlo aquís?

El estudio de las reformas políticoadministrativas de los Borbones plantea la cuestión de la importación en España de un supuesto modelo político francés. En lo que se refiere a la Península ibérica, ésta fue mencionada en dos ámbitos esenciales: las reformas que afectan a la administración central en Madrid y sus relaciones con las autoridades locales en Castilla; los decretos de Nueva Planta en la Corona de Aragón. Me atendré al primer punto, que constituye de por sí un amplio campo de investigación. Dejaré de lado, por lo tanto, las relaciones entre las dos políticas.

\section{PARADOJA}

Se sabe que la idea, común desde el siglo XIX, de que las reformas que el primer Borbón en España emprende en su administración eran una mera imitación de las de Luis XIV² fue matizada en los últimos años, en particular con ocasión de la celebración

\footnotetext{
* Este trabajo forma parte de un proyecto financiado por el Ministerio de Educación y Ciencia (HUM-2005 06628 ).

1. El marqués de Puységur al marqués de Torcy, 22/01/1704, MAE, CPE 136, fol. 81. Traducción mía.

2. La bibliografía al respecto es amplísima y se prolonga hasta hoy. Bastará citar la magna obra de Baudrillart, quien asienta esta tesis en el estudio de una voluminosa documentación francoespañola (Baudrillart: 1890).
} 
del tercer centenario del advenimiento de Felipe V. En efecto, esta idea conlleva una paradoja. Por una parte, supone que existe una diferencia fundamental entre las lógicas española y francesa de fines del siglo XVII, por lo que las reformas de Felipe V aparecen como una profunda ruptura. Sin embargo, se suele observar que varias de las medidas que afectan a la organización de la administración central y local cuajan rápidamente para imponerse de forma duradera en el paisaje institucional de la Península: es el caso de la creación de las Secretarías del Despacho dotadas de departamentos específicos (Hacienda, Guerra, Marina, Indias, etc.) y la reforma conexa de la planta de los Consejos, de las reformas del ejército y de la tesorería general.

Esta implantación de nuevas figuras institucionales conoce dos momentos álgidos que corresponden a la presencia de franceses cerca del rey. En un primer momento, se instituye una Secretaría del Despacho de Guerra (septiembre de 1703) -posteriormente, de Guerra y Hacienda (julio de 1705)-, y en relación estrecha con ella un Tesorero Mayor de Guerra (octubre de 1703 y junio de 1705); asimismo, se reforman el control contable y la organización de los ejércitos (1704-1705) ${ }^{3}$. Entre 1713 y 1715 , se suceden disposiciones destinadas a realzar el protagonismo de varios Secretarios del Despacho y de un nuevo Veedor General (el francés Jean Orry) frente a Consejos debilitados ${ }^{4}$, se restablece la Tesorería Mayor de Guerra suprimida en 1709 y, bajo tutela de los Secretarios del Despacho y el Veedor General, se consolida la red de intendentes iniciada por el Conde de Bergeyck en 1712 . En suma, se tiende a reforzar lo que los contemporáneos llaman la vía reservada frente a la vía ordinaria de los tribunales, con el objeto de favorecer la ejecución de las decisiones de un rey cuya autoridad se ve así consolidada ${ }^{6}$.

Ahora bien, el distanciamento entre las cortes de Madrid y Versalles en 1709 y la definitiva expulsión de los principales promotores de las reformas en $1715^{7}$ no suponen el abandono total de éstas. Aunque se restaura en gran parte la planta original de los Consejos en 1715, estos tribunales no recuperan todas sus competencias frente a los

3. Kamen: 1974; Andújar Castillo: 2000; La Guerra de Sucesión en España y América. Actas X Jornadas Nacionales de Historia Militar. Sevilla, 13-17 de noviembre de 2000, Madrid, Deimos, 2001; Castro: 2004; Nava Rodríguez: 2004; Dubet: en prensa (I) y (II).

4. Unas sintesis en Dedieu: 2000 y Castro: 2004.

5. Kamen: 1964; Ibáñez Molina: 1982; Abbad y Ozanam: 1992; Didier Ozanam: 1995; Castro: 2004. Castro aporta una pieza más al dossier, al estudiar las instrucciones a los intendentes redactadas por el francés Orry en 1714.

6. Sobre la alternativa entre vía reservada y vía de los Consejos: López Cordón: 2000; Castro: 2004.

7. Los episodios son conocidos. En 1709, Luis XIV retira gran parte de su ayuda logística a España, distanciándose de Felipe $\mathrm{V}$, quien no admite las negociaciones entabladas por su abuelo con las potencias aliadas; como consecuencia, el embajador francés Amelot es sustituido por un enviado extraordinario. A finnes del año 1714, la nueva reina de España, Isabel Farnesio, exige la expulsión fulminante de la princesa de los Ursinos, camarera mayor de su predecesora y consejera influyente del rey. Conocen también el destierro el francés Orry y el español Melchor Macanaz, mientras algunas de sus criaturas, como Bernardo Tinajero de la Escalera, caen en desgracia. 
Secretarios del Despacho ${ }^{8}$. Asimismo, se mantiene el principio de una tesorería situada bajo el control directo de éstos, y por lo tanto, más apta a ejecutar las órdenes reales, aunque se vacila entre dos soluciones institucionales ${ }^{9}$. En cuanto a los intendentes de provincias, se sabe que se enfrentan a fuertes resistencias. Sin embargo, su desaparición a partir de 1721 no significa la anulación de toda la reforma. En efecto, se intenta mantener la vía reservada, la relación directa entre los Secretarios del Despacho, quienes transmiten órdenes en nombre del rey, y las autoridades locales, sin pasar por los Consejos. Así, la permanencia de intendentes de ejército por una parte y la militarización de ciertos corregimientos en la Corona de Aragón por otra parte buscan garantizarle al rey la ejecución de sus decisiones ${ }^{10}$. El desarrollo de las Secretarías del Despacho confirma la tendencia: varios investigadores del grupo PAPE, con ópticas institucionales o prosopográficas, demuestran que conocen una precoz institucionalización y se imponen como intermediarios preferentes entre el monarca y sus súbditos ${ }^{11}$.

\section{CONTINUIDAD VERSUS IMITACIÓN}

¿Cómo explicar que instituciones presentadas como la mera réplica de un modelo extranjero lograsen funcionar relativamente bien en España? En este caso, el recurso del monarca a métodos coercitivos no explica del todo su éxito. En efecto, a mi modo de ver, si da cuenta del silencio de grupos hostiles a las reformas o perjudicados por ella, no permite entender que, varios grupos, dentro de la administración real y en el seno de las élites municipales, entendiesen el propósito reformador del Borbón y supiesen sacar partido de los cambios, dando así vida a las nuevas instituciones. Por otra parte, tampoco se resuelve la paradoja apelando a una visión progresiva de la historia, heredada del siglo XIX, en virtud de la cual tendría que imponerse necesariamente la solución más racional (lo que exigiría demostrar que las reformas de Felipe V introducían más racionalidad, y definir ésta).

Otra línea de interpretación parte de la continuidad existente entre las reformas del reinado de Carlos II y las de Felipe V, beneficiando aquí el interés renovado de los historiadores por el reinado del último Austria español. Así, las formas de administración de la hacienda se modifican en la segunda mitad del siglo XVII: la concentración

8. Andújar Castillo: 1996; Dedieu: 2000; González Fuertes: 2002; Castro: 2004, IV-I.

9. Por una parte, una Tesorería Mayor de Guerra; por otra, una Tesorería General, instituida en julio de 1718 en conexión estrecha con los intendentes de provincia (Castro: 2004, 337-340), y que engloba la Tesorería Mayor de Guerra y la Tesorería General heredada del siglo XVI. Las dos soluciones alternan entre 1703 y 1749 (Kamen: 1964; Madrazo: 2000; Dedieu: 2000; Dubet: en prensa (II)). Teresa Nava Rodríguez data de diciembre de 1716 la fusión de las dos tesorerías; sin embargo, la documentación que cita sigue hablando de un Tesorero Mayor de Guerra hasta julio de 1718, fecha de la fusión en una Tesorería General de nuevo cuño (2004: 121 ).

10. Andújar Castillo: 2004.

11. Nava Rodríguez: 1996; López Cordón: 1996 a, b y c; 2000; 2004; Castellano ed.: 1996; Castellano y Dedieu dir.: 1998; Franco Rubio: 1996; Franco Rubio, López-Cordón Cortezo y Nava Rodríguez: 1996. 
de las cajas de recaudación de los impuestos y cierta uniformización de sus distritos por una parte, el envío a las provincias de comisarios controlados por el Consejo de Hacienda o, en su caso, el Superintendente de Hacienda, por otra parte, aparecen a los contemporáneos como medidas destinadas a mejorar la visibilidad de las rentas reales desde la Corte, limitando el control que ejercen en su recaudación las oligarquías locales, apoyadas por el Consejo de Castilla' ${ }^{12}$. De forma más general, se busca crear vías alternativas de negociación entre la corona y las comunidades locales, recurriendo a nuevos grupos de mediadores cuya carrera depende más de sus servicios al rey ${ }^{13} . \mathrm{Al}$ mismo tiempo, en la Corte, los tribunales se ven desplazados por el creciente protagonismo del Secretario del Despacho Universal, apareciendo ya la vía reservada como una rutina ${ }^{14}$. Así, Antonio de Ubilla, futuro marqués de Rivas, quien ocupa el cargo a finales del reinado de Carlos II y al principio del de Felipe $\mathrm{V}$, aparece como un hombre poderoso: su acceso cotidiano al rey y su extenso conocimiento de los negocios que pasan por sus manos le permite pesar en las decisiones, en particular financieras, llegando en algunos casos a ejercer responsabilidades directas ${ }^{15}$. En opinión de Luis XIV, podría ejercer una influencia excesiva en un rey joven y poco informado ${ }^{\prime \prime}$. Pero el Secretario del Despacho no es la única figura susceptible de intervenir en la toma de decisiones y en su ejecución al margen de los Consejos. En las dos últimas décadas del reinado de Carlos II, se idearon varias fórmulas extraordinarias para lograr mayor efectividad en la aplicación de las disposiciones reales, aunque sólo algunas de ellas fueron llevadas a la práctica, y de forma efímera ${ }^{17}$.

12. Garzón Pareja: 1981, 489-493; Cárceles de Gea: 1993, cap. 4 y 1995; Dedieu y Ruiz Rodríguez: 1994; Sánchez Belén: 1996, cap. 1; Múñoz Rodríguez: 2003, 89-92, y 2004; Nava Rodríguez: 2004; Andrés Ucendo: en prensa.

13. Ruiz Ibáñez y Muñoz Rodríguez: 2002; Muñoz Rodríguez: 2003.

14. Escudero: 1969; 1979; 1985. López Cordón: 1996b; 1996c; 2000a.

15. Ocupa el cargo desde agosto de 1698 (FICHOZ). Entre septiembre de 1703 y agosto de 1704 , tiene que ceder el despacho de guerra al marqués de Canales, recuperando posteriomente todo el despacho universal. Abandona la secretaría en enero de 1705 al marqués de Mejorada (Castro: 2004; Dubet: 2005 y en prensa (I)). Se cuenta con él para buscar dinero a la víspera del viaje del rey a Italia y se le sospecha de tener interés en la confusión de la hacienda (Instrucciones de Luis XIV al conde de Marcin, embajador, 07/07/1701, en Morel-Fatio y Léonardon ed.: 1898, 29-30; al cardenal de Estrées, cmbajador, 1702, ibict., 72). En 1703, al lado de Orry, negocia contratos de provisión de los ejércitos con hombres de negocios, pronunciándose sobre las mejores opciones (abad de Estrées al marqués de Torcy, 05/01/1703, MAE, CPE 121, fol. 4-8). Controla las rentas sacadas del prorrateo en 1703 (Orry al cardenal de Estrées, 27/02/1703, MAE, CPE 122, fol. 241). En 1704, ya recuperado todo el despacho universal, firma contratos de provisión de los ejércitos en septiembre de 1704 y da órdenes de compras de granos a los corregidores (cartas intercambiadas entre el marqués de Gramont, el de Rivas y Michel Chamillart, septiembre y octubre de 1704 , SHAT, $A^{\prime} 1786, n^{\circ} 166,182,205,243,248$ bis, 250).

16. Instrucciones de Luis XIV al embajador Marcin, 07/07/1701; al embajador Gramont, 27/04/1704, en Morel-Fatio y Léonardon ed.: 1898 , resp. 47 y 95.

17. Así, el marqués de Los Vélez ejerció brevemente la Superintendencia de la Hacienda en 1687, imitado por el conde de Adanero en 1695 (Cárceles de Gea: 1995, 109, 137) y por el cardenal Portocarrero a fines de siglo (Maura y Baviera: 1935,331). Por otra parte, en 1693, se idea un reparto del gobierno en 
Estos cambios en la forma de ejercer la autoridad real en la Corte y en los territorios, leídos como claros precedentes de lo que sucede a principios del reinado de Felipe V, llevaron a varios historiadores a tratar con cautela el concepto de modelo francés. Así, Victoria López-Cordón utiliza comillas para designarlo ${ }^{18}$. Para José Antonio Escudero, la «alta estrategia políticoadministrativa» de marginación de los Consejos obedece menos a un plan preestablecido que a la respuesta inmediata a dificultades de gobierno coyunturales ${ }^{19}$. Asimismo, Julio Muñoz, hablando de la potenciación de nuevas figuras de administradores locales, insiste en la ausencia de un programa previo de centralización, dando a entender que las similitudes entre Francia, España y otros países europeos se deben ante todo a la necesidad de responder a problemas similares ${ }^{20}$. Tales reflexiones rebaten la tesis de la importación de un modelo distinto. Al suponer que lo que dominó en los cambios observados fue el corto plazo, dan a entender que los actores del cambio aportarían respuestas intuitivas a la urgencia del momento. Poco elaboradas, estas respuestas corresponderían más naturalmente a una lógica política local (aunque extraordinaria) que a modelos importados -que requerirían más reflexión. Esto contribuye a descartar la idea de una influencia francesa.

No obstante, estos historiadores no reivindican un casticismo español o castellano. Se trata de explicar por qué fue posible el cambio: las reformas promovidas por los franceses a principios del siglo XVIII, en cierto modo, eran inteligibles para los españoles que las secundaron o, en su caso, beneficiaron de ellas, porque ya habían imaginado o aplicado soluciones comparables antes de 1700. Creo que, al señalar que los hombres que poblaron las nuevas Secretarías del Despacho en el siglo XVIII no se comportan como modernos burócratas, ni por sus aspiraciones sociales ni por sus vías de promoción, López-Cordón apunta en la misma dirección ${ }^{21}$. La consecuencia es clara: se supone que no hay diferencias sustanciales entre las lógicas políticas española y francesa a principios del siglo XVIII, sino que los dos países forman parte de un mundo común. Conviene señalar, de pasada, que tal conclusión corrobora críticas recientes a la aplicación de los conceptos de nación y nacionalismo a realidades políticas del Antiguo Régimen ${ }^{22}$.

\section{EN BUSCA DE LAS REPRESENTACIONES}

Admito la conclusión -no se puede hablar de un modelo francés y un modelo español-, pero creo que merecería apoyarse en más argumentos.

el territorio peninsular entre cuatro lugartenientes del rey, aunque no se sabe si sus competencias serían sólo militares o más amplias (Ribot García: 1993, 128-129). En 1700, el marqués de Leganés imagina confiar a juntas ad hoc el gobierno de distintas partes del territorio, minando el poder de los Consejos, que rechazan la iniciativa (Baltar Rodríguez: 1998, 143-144).

18. López Cordón: 2000.

19. Escudero: 1985, 101.

20. Muñoz Rodríguez: 2003 y 2004.

21. López-Cordón: 1996c, 853.

22. Hespanha: 1992; Peytavin: 1998; Schaub: 2001; Gil Pujol: 2002. 
En efecto, el razonamiento se basa en una comparación doble, por una parte, entre el funcionamiento de la administración española después de la Guerra de Sucesión y las reformas anteriores a $1700 \mathrm{y}$, por otra parte, de forma más implícita, entre lo que pasa en ambos lados de los Pirineos ${ }^{23}$. Esta comparación se funda esencialmente en la descripción de formas institucionales, de circuitos de circulación de la información y documentación administrativa, de las competencias de los órganos creados o afectados por las reformas o de recurrencias en las trayectorias individuales y los vínculos interpersonales. Así, tiende a la objetividad. De hecho, gran parte de la documentación manejada en los estudios relativos a las primeras reformas políticoadministrativas de Felipe $\mathrm{V}$ o las de su predecesor se compone de los decretos, órdenes u ordenanzas que instituyen nuevos órganos administrativos o modifican los existentes o de las fuentes que permiten reconstruir redes de relaciones. Aunque tales documentos no carecen de indicaciones sobre las razones que motivaron las reformas, suelen ser escuetas. Además, contienen escasas informaciones sobre las modalidades concretas de la puesta en marcha de las nuevas disposiciones y la forma como las interpretaron los contemporáneos.

Esta presentación objetiva suscita objeciones. En efecto obliga a los historiadores, de forma casi inevitable, a colmar el vacío haciendo hipótesis sobre los objetivos políticos de los promotores de las reformas y sus adversarios y sobre el significado que dieron a su acción. En los ejemplos citados, López-Cordón se interroga acerca de la mentalidad de los nuevos agentes de la administración borbónica, mientras Escudero se pregunta si primó la táctica sobre la estrategia. Si estos dos historiadores optan por desconfiar de una lectura finalista y en gran medida anacrónica -la que ve en las reformas borbónicas la aplicación metódica de un programa de racionalización administrativa de cuño francés-, cabe imaginar que otros, con idéntico método, lleguen a conclusiones opuestas.

Un riesgo añadido de la descripción objetiva de las reformas borbónicas consiste en mantener separadas las trayectorias de distintas instituciones, reflejando la separación de los archivos que produjeron. Así, se pasan por alto las relaciones que establecieron los promotores de las reformas entre varias disposiciones simultáneas, difuminándose parte de su significado. El caso de las Secretarías del Despacho, las intendencias de provincias y las modificaciones de las Tesorerías centrales constituye un ejemplo paradigmático de esta actitud. Así, algunos autores comprobaron que en 1703, la Tesorería Mayor de Guerra y la Secretaría del Despacho de Guerra se crean de forma simultánea y, después de ser suprimidas en el verano de 1704, vuelven a crearse las dos entre junio y julio de 1705 (extendiéndose el departamento de la segunda a la Hacienda). Otros, o los mismos, señalaron que la iniciativa de las dos se debe

23. A excepción de Baudrillart, pocos de los autores citados hasta aquí describen lo que sería el modelo francés. Sin embargo, Francisco Javier Guillamón Álvarez ha llamado la atención sobre su naturaleza problemática (2000). 
al mismo individuo, Jean Orry ${ }^{24}$. Sin embargo, Concepción de Castro es la única en explicitar el vínculo que existe entre Tesorero Mayor y Secretario del Despacho de Guerra: los dos forman parte de un mismo dispositivo cuyo objetivo es modificar los resortes del control financiero sobre el ejército. El análisis que la historiadora dedica a las relaciones de trabajo cotidiano entre los primeros titulares, el conde de Moriana (Tesorero), el marqués de Canales (Secretario del Despacho de Guerra en 1703-1704) y José Grimaldo (Secretario del Despacho de Guerra y Hacienda a partir de julio de 1705 ), confirma su hipótesis, aunque no detalla las modalidades del control aludido ${ }^{25}$. De forma idéntica, la simultaneidad entre la creación de intendentes de provincias, contadores de provincias y una Tesorería General que absorbe la Tesorería Mayor de Guerra y la antigua Tesorería General en julio de 1718 ha sido advertida por los historiadores de los intendentes. Éstos notan que cuando se da marcha atrás en la primera reforma en 1721, se suprime la Tesorería General ${ }^{26}$. Aquí también, varios investigadores propusieron explicaciones de tales concomitancias. Así, Francisco Andújar Castillo indica que a partir de 1714 se reserva la comunicación con los comisarios de guerras, los inspectores, intendentes y tesoreros al Secretario del Despacho de Guerra. Esto implica que el último ejerce cierta forma de tutela sobre los otros y el conjunto de estos nuevos agentes se destina a ocupar un espacio otrora reservado al Consejo de Guerra, el de la elaboración de la política militar y el control de su ejecución ${ }^{27}$. Cabe imaginar que tal propósito fue el de los iniciadores de la reforma de 1703 o de la de 1718, pero sería deseable verificarlo. Por otra parte, Jean-Pierre Dedieu y José Ignacio Ruiz Rodríguez explicitan la complementariedad entre tres figuras en la hacienda, los ordenadores (quienes emiten las órdenes de pago), los detentadores de las cajas (quienes los ejecutan), los encargados del control de la buena ejecución, invitando a analizar la circulación de la información entre las tres entidades. El esquema, común en Europa, es aplicable a la reforma de julio de 1718: a nivel provincial, una «troika» constituida del intendente (ordenador), el pagador y el contador; en la Corte, sus respectivos órganos de tutela, el o los Secretarios del Despacho, el Tesorero General y las Contadurías de Valores y Distribución (instituidas en 1717 ) $^{28}$. Sin embargo, Castro es la única en analizar de forma conjunta las instrucciones redactadas para los intendentes, los pagadores y los contadores de provincias en aquella fecha ${ }^{29}$.

En suma, en este caso preciso, los historiadores se ven condenados a imaginar una relación plausible entre disposiciones que la documentación manejada presenta

24. Kamen: 1974; Castro: 2000 y 2004; Nava Rodríguez: 2004. Sobre el secretario: Baudrillart: 1890; Escudero: 1969 y 1979; López Cordón: 2000; Castellano: 2002, 38. Kamen (1974) y Didier Ozanam (1995), seguidos por otros (Alamo Martell: 1997; Castro: 2004) indican que le correspondió a Orry la iniciativa de la creación del Tesorero Mayor de Guerra.

25. Castro: 2004.

26. Kamen: 1974; Ibáñez Molina: 1982; Abbad y Ozanam: 1992; Didier Ozanam: 1997, 183.

27. Andújar Castillo: 1996.

28. Dedieu y Ruiz Rodríguez: 1994.

29. Castro: 2004. Nava Rodríguez (2004) resume las de los contadores y pagadores. 
por separado. Pocos han ido más allá, buscando otros tipos de fuentes que explicitasen cómo los propios contemporáneos concebían estas relaciones. El aporte decisivo de Castro consiste en estudiar por primera vez el trabajo cotidiano de las oficinas de las Secretarías del Despacho ocupadas por Canales y Grimaldo en un período largo. Así, pone de realce las relaciones que tejen con los responsables locales (los intendentes, cuando los hay, pero también los corregidores, gobernadores de armas, generales de ejércitos, obispos, etc.), y en menor medida el tesorero y sus agentes en las provincias. De pasada, revela la flexibilidad del plan de reforma inicial. No obstante, la relación entre la creación de un Secretario del Despacho de Guerra, o de Guerra y Hacienda, con los sucesivos tesoreros y, aun más, los órganos encargados del control financiero, ha sido infravalorada ${ }^{30}$, lo que implica omitir una función importante de los nuevos Secretarios. Asimismo, subsisten varias incógnitas. Por ejemplo, no se sabe por qué se pasa de un Secretario del Despacho de Guerra en 1703 a otro de Guerra y Hacienda en 1705, ni por qué el esquema que une al Veedor General con el Secretario de Guerra y Hacienda, el Tesorero Mayor de Guerra y los superintendentes de provincias en 1714 se sustituye por otro en 1718 - a partir de esta fecha, la existencia de intendentes de provincia supone la supresión de la Tesorería Mayor de Guerra, y viceversa.

Para comprender estos matices, nos hacen falta los proyectos de los contemporáneos que prepararon las reformas, así como sus evaluaciones e interpretaciones de las mismas ${ }^{3 !}$. Asimismo, disponer de elementos que expliciten la lógica global de las reformas políticoadministrativas de los Borbones constituye un punto de partida a la comparación con posibles modelos exteriores.

\section{4. ¿QUÉ FRANCIA IMITAR?}

Sin embargo, en el presente caso de las primeras reformas de los Borbones en España, la historia comparada que podemos realizar los historiadores me parece insuficiente si se quiere plantear la cuestión de la posible importación de un modelo francés. Precisamente porque los propios actores hablaron explícitamente de imitación, para promoverla, rechazarla o negarla, resulta difícil dejar de lado las comparaciones que ellos mismos establecieron. De forma empírica, esta perspectiva puede contribuir a definir los límites de lo que puede o debe compararse y por lo tanto a delinear eventuales modelos. Así, Francisco Javier Guillamón Álvarez pone el dedo en la llaga cuando pregunta si el Versalles que imitaría Felipe $V$ es el de la vejez austera de Luis XIV o el de una juventud más lúcida, y si la forma de gobierno de los Borbones franceses que le inspira es la que el rey Sol inaugura en 1661 o el gobierno de los tribunales (la llamada «polisinodia») que se «restaura» durante la Regencia, y corresponde a una práctica

30. Ozanam (1995) y Dedieu $(2002,392)$ señalan la ausencia de una monografía sobre la Tesorería General de 1718.

31. Intento completar este panorama para los inicios del siglo XVIII (hasta 1706) en Dubet: 2005; 2006; en prensa (1). 
del siglo $\mathrm{XVII}^{32}$. En la misma línea, es legítimo preguntar si conviene comparar las realizaciones de Felipe V y de Luis XIV o sus proyectos, como lo hace Marta Ruiz Jiméne $z^{33}$.

Tomar en cuenta las comparaciones establecidas por los contemporáneos y sus eventuales referencias a una imitación de la Francia de Luis XIV por parte de España no significa volver a un punto de partida que podría ser ejemplificado por la tesis de Alfred Baudrillart, la de una influencia de la corte de Versalles en Madrid que se traduce por la reproducción en España de un modelo políticoinstitucional francés. De hecho, no se puede negar que numerosos actores y testigos de las primeras reformas borbónicas atribuyen a Felipe V y su entorno la explícita voluntad de imitar a Luis XIV y reproducir en España las instituciones francesas. Así lo afirma el marqués de Torcy, Ministro de Relaciones Exteriores, presentando a Luis XIV como ejemplo a seguir en sus instrucciones al embajador Marcin, en julio de 1701:

«la nación en general espera, como principal efecto de la unión de Su Majestad [Luis XIV] con el Rey Católico, que sus luces y prudencia disiparán por fin la confusión introducida durante los anteriores reinados en todos los negocios y restablecerán el orden en España, tal como vemos que se observa en Francia, bajo el gobierno de Su Majestad) ${ }^{34}$

Meses más tarde, el propio Luis XIV se reconoce en las reformas del otoño de 1703 -la creación del Tesorero Mayor de Guerra y el Secretario del Despacho de Guerra. Así lo escribe a su nieto: «Estas dificultades no me impidieron establecer en mi reino la misma regla para el pago de mis tropas. $\rangle^{35}$

El esfuerzo de reproducción de reglamentos o instituciones francesas se afirma en el terreno militar. Así, las ordenanzas militares de abril de 1702, atribuidas al marqués de Puységur, se abren con un preámbulo que justifica la reforma por la necesidad de armonizar los criterios de subordinación de las tropas francesas y españolas; de hecho, algunos artículos son reproducciones textuales de disposiciones tomadas en Francia,

32. Guillamón Ảlvarez: 2000.

33. Ruiz Jiménez: 2000. Esta historiadora critica así la idea de un modelo de monarquía fijo en el tiempo, que correspondería al ejercicio del gobierno de Luis XIV y sería el de un proceso racionalizador, centralizador y uniformizador, en el que una monarquía administrativa buscaría reducir al máxino los privilegios estamentales, en particular fiscales. En su opinión, este modelo se desvirtúa a partir del reinado de Luis XV, poniéndose freno a la racionalización administrativa y desapareciendo la justicia y la uniformidad fiscal, o incluso antes, en el caso de los intendentes. Comparto este punto de partida, la necesidad de tomar en cuenta la evolución de la práctica política en el supuesto modelo francés. Pero creo que la pintura que hace la autora de la forma de gobernar de Luis XIV es un tanto esquemática, por ejemplo cuando afirma que los intendentes de provincia empezaron siendo instrumentos locales del absolutismo para convertirse a la larga (como una degradación del modelo original) en hábiles negociadores al servicio del monarca. En efecto, numerosos estudios autorizan a pensar que esta dinámica negociadora fue constitutiva de la figura de los intendentes (ver las sintesis de Emmanuelli: 1981; Smedley-Weill: 1995, cap. III; Chaline: $2005,312-348$ ). En cuanto a la idea de que la monarquía absoluta tendia a eliminar los privilegios fiscales, contradice el trato privilegiado otorgado por Luis XIV a las diferentes categorias de nobleza.

34. Léonardon y Morel-Fatio: 1898, 5. Traducción mía.

35. Luis XIV a Felipe V, 13/08/1703, MAE, CPE 124, fol. 531. Traducción mía. 
como las relativas al pago de la masa ${ }^{36}$. Elaboradas en Flandes, sirven posteriormente de referencia en España ${ }^{37}$ e interviene de nuevo Puységur en la preparación de las de septiembre de 1704, que introducen los regimientos en el ejército peninsular ${ }^{38}$. Así, no sorprenderá encontrar bajo la pluma de este caballero el epígrafe de este artículo.

La imitación también afecta las formas de la alta administración. En muchas ocasiones, ni siquiera es necesario mencionar la fuente de inspiración: la simple traducción la revela. Así, en 1702, Orry pretende reorganizar los Consejos instituyendo un Consejo real que recuerda al «Conseil du roi» establecido por Luis XIV en 1661, después de la muerte de Mazarino. Reconociendo el carácter extraño de su innovación en España, el francés aconseja otra denominación: se le podría llamar «despacho» para que parezca «menos nuevo ${ }^{39}$. La composición de esta nueva forma de Consejo también se inspira en su alter ego francés. La presencia de unos intendentes de hacienda o de comercio situados bajo la tutela de un Veedor General recuerda la organización del Consejo de Luis XIV a partir del momento en que Colbert, elevado a las funciones de «Contrôleur Général», ingresó en él ${ }^{40}$. En cuanto al Secretario del Despacho de Guerra creado en 1703, los franceses lo suelen denominar «Secrétaire d'État à la Guerre», reconociendo en él un equivalente de Louvois, Barbezieux y Chamillart ${ }^{41}$. Por fin, el Tesorero Mayor de Guerra recibe denominaciones fluctuantes ${ }^{42}$. Sin embargo, Puységur lo llama sin vacilar «trésorier de l'extraordinaire du Roi d'Espagne» ${ }^{43}$, una clara referencia a los «Trésoriers de l'Extraordinaire des Guerres» de Francia. Asimismo, los agentes del nuevo Tesorero en los ejércitos, los pagadores, se designan como los «cometidos» en las ordenanzas de $1705^{44}$. Es difícil imaginar traducción más literal.

De forma más general, sirve de referencia recurrente la misma persona de Luis XIV, como ejemplo de rey capaz de gobernar «solo» o «por sí solo». Se sabe que el propio monarca francés reivindicó esta capacidad como su mayor innovación a la muerte de Mazarino, haciendo de ella un uso que se podría calificar de propagandístico

36. Portugués: 1764, t. I, p. 276-277, 286, 296-299, 314-17. Gachard (1867, 17-18) atribuye la preparación del texto a Puységur. Éste, una vez en España, comentando la política militar de Orry, dice que hizo lo mismo en Flandes (carta a Chamillart, 11/01/1704, SHAT, $\mathrm{A}^{1} 1787, \mathrm{n}^{\circ} 16-18$ ).

37. Puységur a Chamillart, 21/01/1704, SHAT, $\mathrm{A}^{1} 1787, \mathrm{n}^{\circ} 39-40$.

38. Ozon (secretario de Puységur) a Torcy, 17/09/1704, MAE, CPE 139, fol. 50-54. Sobre las ordenanzas de 1701, 1702 y 1704: Andújar Castillo: 2000; Pablo Cantero: 2001; Parejo Delgado: 2001; Claro Delgado: 2001. Se pueden consultar en Portugués: 1764, t. I, p. 371 y sigs.

39. MAE, CPE 119, fol. 197.

40. Aunque el texto está redactado en francés, Orry sólo utiliza las palabras españolas. Sobre este proyecto y su inspiración francesa: Dubet: 2005 y Dubet: en prensa (I), cap. 4.5 y 4.6.

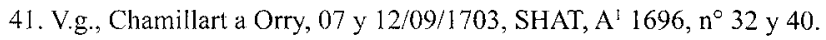

42. Trésorier Général, Trésorier pour les Fonds de la Guerre, pour les Dépenses de la Guerre, Trésorier Général de la Guerre, Trésorier de la Guerre, Trésorier pour la Guerre (MAE, CPE 120, passim).

43. Puységur a Chamillart, 04/03/1704, SHAT, $\mathrm{A}^{1} 1787, \mathrm{n}^{\circ} 139$.

44. «Real ordenanza para la formalidad de las revistas, que los comisarios de Guerra han de pasar a las tropas: equipages, tren de artillería y víveres de los ejércitos, como también de lo que se ha de observar por los tesoreros y asentistas de pan y cebada» (Portugués: 1764, t. X, p. 327 y sigs.). 
-así, la fórmula no sólo aparece en las Memorias al Delfín sino también como título de un cuadro de la Galería de los Espejos de Versalles ${ }^{45}$. Incluso llegó a vanagloriarse de servir como modelo para otros príncipes, como Felipe $\mathrm{IV}^{46}$. Los prolijos memoriales de Colbert glosaban esta nueva figura real ${ }^{47}$. Además, tanto el monarca francés como su Veedor General habían detallado la aplicación de esta actitud inédita a la hacienda: la institución de un "Conseil Royal des Finances» presidido por el rey, un monarca que «ordenaba» personalmente los gastos y los controlaba por sí solo, examinando las cuentas cada mes con su ministro ${ }^{48}$. La ilustración iconográfica no se hizo esperar: un cuadro de Versalles representa «el orden restablecido en la hacienda», acontecimiento fechado en $1662^{49}$.

Ahora bien, el imperativo de que Felipe $\mathrm{V}$ aprenda a gobernar solo se repite hasta la saciedad en la documentación intercambiada entre las cortes de Francia y España a principios del siglo XVIII. Así, Orry, iniciador de las reformas políticoadministrativas de principios del siglo, insiste en la necesidad de restaurar la «autoridad real», para que el rey pueda portarse como el «amo», nombrar «por sí solo» en todos los cargos, dar sus órdenes en materia de guerra «por sí solo» y asimismo «gobernar su hacienda por sí solo»: en suma, «instruir y conducir todos sus negocios por sí solo» ${ }^{50}$. Una vez establecidas las reformas en 1703, triunfa: Felipe V «actúa por sí mismo» y supo «superar la timidez que hizo que lo creían incapaz de gobernar»; el monarca trabaja «regularmente todos los días un mínimo de seis horas» y escribe sus cartas «de su puño y letra» ${ }^{51}$. Pero Orry no es nada original en sus invitaciones a enseñarle a Felipe $\mathrm{V}$ a ser el verdadero amo y gobernar solo, aunque insiste más que otros en la aplicación financiera de la fórmula. Tales invitaciones aparecen como un tópico de la correspondencia intercambiada entre Madrid y Versalles ${ }^{52}$. Algunos explicitan la imitación: para el mariscal de Tessé,

45. Luis XIV: 1978, 49-50; Conette: 2000a, cap. 9 y 1996.

46. «Me demostró [Felipe IV] la estima en que me tenía de un modo que, lo confieso, me halagó, cuando, después de la muerte de don Luis de Haro, dijo públicamente en presencia de todos los embajadores de los príncipes extranjeros que para seguir mi ejemplo ya no quería tener primer ministro. Pues me parecía a la vez muy generoso en lo que le tocaba, y muy glorioso para mí, que aunque él tenía tanta experiencia de los negocios reconociera que yo le había servido de guía en el camino de la realeza. Y sin vanagloriarme demasiado, tengo buenas razones para creer que en este mismo punto muchos otros príncipes se fijaron en mi conducta para determinar la suya.» (Luis XIV: 1978, 131).

47. Cornette: 1996; 2000a, 3" parte; 2000b, 15-17.

48. Luis XIV: 1978, 49-50, 83-87, 107, 217; Colbert: 1863-1873, I, p. CXCVI, 83-88 y 1873, VII, 164-183; Dessert: 2000, 134-135. Sobre las competencias de este nuevo Conseil Royal des Finances y el reparto del trabajo con el Contrôle Général encabezado por Colbert: Antoine: 2003.

49. Cornette: $2000 \mathrm{~b}, 125$.

50. BNF, Nouvelles Acquisitions, Ms 10228, fol. 1-28, memorial del 20/03/1705 sobre el despacho; MAE, CPE 122, fol. 283-289, memorial del 03/03/1703 sobre el despacho; CPE 119, fol. 208, 217, 248 (memoriales de diciembre de 1702), 341 (Orry a Torcy, 23/05/1703), 357 («Projet des ordres à donner sur les troupes, suivant les intentions du Roi d'Espagne», 30/06/1703). Traducción mía.

51. Orry a Torcy y Chamillart, 05/10/1703, resp. MAE, CPE 120, fol. 148-163 y SHAT, A 1696, $n^{\circ} 56$.

52. Se encuentran parecidas fórmulas en cartas del caballero Du Bourck (02/09/1705, MAE, CPE 151, fol. 128-131; 30/09/1705, ibid., fol. 171-175), Amelot (10/06/1705, MAE, CPE 147, fol. 143-149), 
aunque no hay proporción entre el talento y la prudencia de Luis XIV y la juventud de su nieto, éste debe seguir las huellas de su abuelo ${ }^{53}$.

Se podrían multiplicar las citas. Conviene señalar que éstas son tanto más abundantes cuanto que alimentan la visión que muchos historiadores franceses del siglo XIX tuvieron de esta etapa de la historia española. Así, se pueden rastrear frases similares en las correspondencias o colecciones de documentos editadas en aquel siglo o en las monografías de autores que, como Baudrillart, frecuentaron con asiduidad los archivos de los ministros Chamillart y Torcy.

\section{CONTEXTUALIZAR: LA AMBIVALENCIA DE LA IMITACIÓN}

Sin embargo, estas invitaciones a imitar Francia, bajo la pluma de franceses, no demuestran que hay un modelo francés, o sea, que lo que se imita es exclusivamente francés. En efecto, se pueden interpretar en sentido distinto.

Primero, conviene notar que, aunque algunos hablan de Francia, los más evocan a Luis XIV, o sea la práctica (idealizada) de un rey y no el talante de un reino o una nación. Sería útil verificar que establecen una distinción entre los dos y en qué consiste.

Pero sobre todo, la misma posibilidad de imitar Francia es ambivalente. Si por una parte parece significar que España es distinta de Francia e imitarla es un cambio, por otra, implica que los remedios franceses pueden servir en España, o sea que son adaptables e inteligibles. Esto reduce la distancia entre dos modelos a priori distintos. Así, es revelador observar que las mismas plumas que subrayan la diferencia entre España y Francia de un lado desarrollan, de otro lado, la idea de un paralelismo en la historia de los dos países. Es el caso de Tessé. Las tensiones con los Grandes y el hecho de que algunos de ellos se pasaron al bando austracista le recuerda la Fronda, aunque la situación española es peor que cuando Luis XIV tuvo que abandonar París. Por lo tanto, conviene cambiar el gobierno como lo hizo Luis XIV cuando «llevó [Vuestra Majestad] sus negocios y su reino al punto culminante de gloria y autoridad en que los vemos hoy $\rangle^{54}$. Para Puységur, se impone el mismo paralelo con la Francia de la minoría de Luis XIV: «todas las desórdenes de este país existían en Francia durante la minoría del Rey» ${ }^{55}$. Ya comprobamos que Luis XIV comparte esta visión: al comparar la política de Felipe $V$ con la suya, habla en pasado, refiriéndose a su juventud.

Que ninguno de los tres crea necesario desarrollar y justificar el paralelo es una señal de que lo consideran como evidente para los destinatarios de sus cartas. Por lo

Chamillart (01/10/1704, SHAT, $\left.\mathrm{A}^{1} 1786, \mathrm{n}^{\circ} 205\right)$, Luis XIV (03/05/1703, en Millot: 1828, II, $244 \mathrm{e}$ «Instructions» a Marcin, 07/07/1701, Léonardon y Morel-Fatio ed.: 1898), la princesa de los Ursinos (06/12/1706, en Millot: 1828, II, 398), Torcy (04/02/1703, MAE, CPE 121, fol. 148-150; 23/10/1703,

MAE, CPE 120, fol. 173-180)

53. Tessé a Chamillart, 14/06/1705, SHAT, $\mathrm{A}^{\prime} 1885, \mathrm{n}^{\circ} 212$.

54. Tessé a Chamillart, 14/06/1705, SHAT, $\mathrm{A}^{\prime} 1885, \mathrm{n}^{\circ} 212$. Traducción mía.

55. Cfr. n. 2. 
tanto, bien podría constituir un tópico compartido por los que intervienen en los asuntos españoles a principios del siglo XVIII. Convendría documentarlo más para poderlo afirmar. De momento, bastará señalar que las investigaciones de Ana Álvarez López y Jean-Frédéric Schaub sobre la visión que los franceses del siglo XVII tenían de los españoles les llevan a parecida conclusión. Ambos historiadores insisten en efecto en la «ambivalencia» de la mirada de los franceses, demostrando que la «antipatía» entre las naciones procede más de la conciencia de su similitud que de sus diferencias y, por lo tanto, es el efecto de su rivalidad. El segundo analiza los discursos relativos a la imagen de los monarcas y a los proyectos imperiales mostrando que España y Francia comparten una misma aspiración a la monarquía universal y que el «arte de gobernar», para muchos autores, es más español que francés ${ }^{56}$.

Estudios como los de Schaub y López Álvarez evidencian la necesidad de contextualizar los discursos, en este caso, de los franceses relativos a España. Sacada de su contexto histórico y textual, una frase programática que invite a Felipe $\mathrm{V}$ a imitar a su abuelo puede suscitar la interpretación que le dio Baudrillart. En cambio, tomar en cuenta el discurso integral de los actores puede llevar a lecturas distintas. La ambivalencia de discursos como los de Tessé, Puységur o el mismo Luis XIV -quienes por una parte subrayan la confusión que reina en España y la debilidad de su rey y, por otra, creen que Felipe $V$ es capaz de aplicar la misma política que su abuelo y esta política tendrá éxito en su país- obliga a preguntarse cuándo y por qué se insiste en la diferencia española. Además, resulta necesario ir más allá de las afirmaciones programáticas, reconstituyendo cuando es posible el «contenido» que los actores atribuyen al supuesto modelo francés, en particular su contenido institucional. Puede ser en efecto una forma de comprobar la originalidad de éste.

En lo que se refiere a los primeros años del siglo XVIII, es un trabajo que queda por hacer en gran parte. Sin embargo, el estudio de la correspondencia de monarcas, embajadores y otros franceses presentes en España en los años anteriores y posteriores a 1700 autoriza algunas hipótesis. El tema de la decadencia, que a priori tiende a demostrar la radical alteridad española, ofrece un buen punto de partida. Así, se observa que todos coinciden en describir una monarquía «arruinada» aduciendo los mismos síntomas: la despoblación, las derrotas militares, la pobreza del rey y de la Corte, la ausencia de manufacturas, etc. Los esquemas explicativos también son similares y se inspiran en parte en los discursos de los propios españoles sobre la «declinación». Los «abusos», en particular los de los Grandes que controlan los Consejos, pero también los de los agentes de la administración fiscal, explican a la vez la «confusión» (por los conflictos entre los Grandes), la debilidad de la «autoridad» del rey (los Grandes pretenden usurparla), la pobreza del soberano (sus agentes en las provincias le roban, la venalidad de oficios beneficia a los Consejeros y Grandes y no al monarca) y la de los súbditos (agobiados por una costosa administración fiscal). De forma más general, pereza y pundonor constituyen un freno a las actividades productivas y al desarrollo

56. Álvarez López: 1999; Schaub: 2003. 
de la milicia. Los acontecimientos históricos que pesaron en la balanza también son los mismos: la expulsión de las minorías religiosas, la emigración hacia América, el envío de numerosos soldados a Italia y Flandes. A la repetición de los argumentos, se añade la imprecisión factual: la mayor parte de los autores de estos textos se contentan con juicios calificativos, sin evaluar el volumen de la despoblación o de la ausencia de manufacturas ${ }^{57}$; por otra parte, las fechas en que habría empezado el proceso de decadencia varian de un autor a otro, pero tampoco se justifican.

En suma, la pintura de una España que «perece» parece ser un tópico que se encuentra bajo la pluma de actores que, por otra parte, propondrán formas diversas de actuar en la Península ${ }^{58}$. Más que una creencia profunda, este tópico aparece como una etapa del discurso. En efecto, los actores se valen de esta descripción para justificar la necesidad de introducir cambios en España, para restaurar su «prístina grandeza» o «recomponer» la monarquía ${ }^{59}$. Pero a partir del momento en que quieren demostrar que una reforma es factible y tendría éxito, los mismos actores insisten en las buenas disposiciones del país, sus riquezas sin explotar o el dinamismo de sus habitantes, así como los viajeros franceses del siglo XVII veían en la corrida y las hazañas amorosas de los cortesanos una señal de vitalidad ${ }^{60}$. Para el embajador Harcourt, el rey de España «conservó toda la autoridad necesaria», aunque «no fue empleada para sostener la justicia, que es sin embargo su uso más natural» -lo que justifica una intervención francesa ${ }^{61}$. Para Luis XIV, «la nación española ha producido grandes hombres, tantos como cualquier otra nación, y pueden surgir otros $\rangle^{62}$. Quien mejor ilustra esta postura intelectual es, sin duda, Jean Orry, quien después de pintar la decadencia del país, elabora un ambicioso programa reformador basado en la idea de que las riquezas humanas y materiales existen, pero fueron mal administradas ${ }^{63}$.

Si los discursos sobre la decadencia parecen demostrar que un abismo separa España y Francia, los discursos reformadores tienden en cambio a borrar las diferencias entre los dos países, con lo que la imitación de las reformas políticas de Luis XIV no sería la importación de un modelo extranjero. Es aquí donde resulta interesante fijarse en el contenido institucional de los discursos contrastados sobre Francia y España. Para los franceses contemporáneos, el cargo del Secretario del Despacho Universal a fines

57. El marqués de Villars (embajador entre 1671 y 1673 y entre 1679 y 1682) ofrece una excepción cuando cita el memorial de un diputado del comercio de Sevilla quien, en 1680, daba medidas concretas de la despoblación de la ciudad y la desaparición de manufacturas (Villars: 1893, 6-7).

58. Dubet: en prensa (1), cap. 2.1.

59. Chamillart a Gramont, 06/09/1 704, SHAT, $\mathrm{A}^{1} 1786, \mathrm{n}^{\circ} 156$; Chamillart a Portocarrero, octubre de 1702 , Hanotin: 2003, 59 y Saint-Simon: 1879, XI, 242; Gramont a Chamillart, 19/09/1704, SHAT, A 1786 , n 182. Traducción mía.

60. Sobre este último punto: Álvarez López: 1999, $91-92$.

61. Harcourt a Chamillart, 25/02/1701 (Chamillart: 1978, I, 23-25). Traducción mía.

62. «Instructions au Duc de Gramont», 27/04/1704, Léonardon y Morel-Fatio ed.: 1898, 117-118. Traducción mía.

63. Dubet: en prensa (l), cap. 4. 
del siglo XVII concentra las cuatro Secretarías de Estado francesas ${ }^{64}$ : de este modo, la división entre varios departamentos iniciada en 1703 no sería tan extraña. En la hacienda local, Orry establece un interesante paralelo entre los intendentes de provincia franceses y los corregidores. Por otra parte, observa que las formas de recaudación de los impuestos provinciales y de negociación de la carga fiscal con las autoridades locales no son distintas -para él, las rentas provinciales ya se recaudan como la «taille». En suma, sus propios proyectos de reforma no significarían la imposición en España de un modelo alternativo, sino la sistematización de la práctica existente ${ }^{65}$. La política de sistematización de la venalidad de oficios que Orry y su entorno desarrollarán durante la Guerra de Sucesión constituye una ilustración convincente de esta postura ${ }^{66}$.

\section{HACER LO EXTRAORDINARIO ORDINARIO}

La dificultad que surge en cuanto se intenta concretar el contenido políticoinstitucional que los contemporáneos atribuyen al modelo francés sugiere otros ángulos de observación.

El primero se sitúa en clara continuidad con la interrogación anterior. Convendría aplicar las preguntas que ya se enunciaron para los discursos de los promotores de las reformas al discurso de los que, en España y en Francia, se oponen a ellas. En efecto, sería una forma de saber si los contemporáneos comparten la idea de que los dos países encarnan dos lógicas políticas distintas, aunque unos y otros las valoran de forma opuesta. En otros términos, se pregunta si los que se oponen a las reformas de Felipe V defienden un modelo español y qué contenido concreto le atribuyen. ¿Consideran que las reformas de Felipe V constituyen una ruptura? ¿Cómo la califican?

Los indicios de que dispongo para los primeros años del siglo son pocos, pero todos apuntan en la misma dirección. Cuando Orry, la Princesa de los Ursinos y posteriormente Amelot emprenden las reformas mencionadas arriba, se enfrentan ante todo a una resistencia silenciosa, una inercia calculada. Sin embargo, algunos van más allá, quejándose de las novedades introducidas y precisando cuáles deberían ser las buenas reglas de gobierno a seguir.

Éste es el caso del cardenal Portocarrero: además de perder el control del despacho en el otoño de 1703, se ve privado del «manejo» del dinero rescatado cuando se destruyó la flota en Vigo en 1702, que el rey le había confiado para que lo aplicara a gastos de guerra. En efecto, este fondo ingresa ahora en la caja del Tesorero Mayor de

64. Así lo expresa Saint-Simon: «Este cargo no tiene nada acá a que corresponda. Son los cuatro cargos de Secretarios de Estado propiamente dichos, todos, tales y cuales son, y tan extendidos y autorizados como acá, fundidos en uno, corte, guerra, marina, negociaciones, provincias, ejercidos por un solo hombre» (Saint-Simon: 1879, VIII, 536).

65. Dubet: en prensa (1), cap. 4.

66. Doy algunas indicaciones sobre ella en Dubet: en prensa (I), cap. 4.4., 4.6.1., 5.1.2., 6. 1.1., 9.2. Francisco Andújar Castillo estudia su desarrollo y modalidades entre 1705 y 1711 , demostrando su amplitud y el papel central desempeñado por el Secretario del Despacho de Guerra y Hacienda (en prensa). Agradezco al autor el haberme mostrado su texto inédito. 
Guerra, dando las órdenes de gasto el Secretario del Despacho de Guerra, el marqués de Canales. Un año más tarde, el eclesiástico aprovecha la rendición de sus cuentas para elevar al rey una sonada protesta. Sus cuentas, apunta, se prolongan «hasta fin de octubre de 1703 que se alteraron y mudaron de mano y conducta las cosas de la guerra». Se apoyan en relaciones

«calificadas por los Consejos, tribunales y ministros por donde dirigí mis operaciones para el más acertado, seguro y puntual cumplimiento de lo que Vuestra Majestad me mandó, arreglándome en todo a la loable práctica y estilo observado en el gobierno de estos reinos, con cuya concorde armonía salen más felices las deliberaciones.»

En otros términos, Portocarrero siempre se esforzó por «no extraviar el curso regular» de los negocios. Esto significa que cada decisión fue aprobada por los Consejos competentes: el cardenal dio órdenes para el gasto y para levantar tropas a los capitanes generales, gobernadores y otros ministros pasando por la «vía ordinaria del Consejo de Guerra»; se dirigió a villas, ciudades, gentilhombres y particulares pasando por el Consejo de Castilla; las libranzas para mantenimiento de tropas fueron preparadas por el Consejo de Hacienda. Esto permitió procurar que los fondos «no se disipasen en adelante como por lo pasado se había experimentado, y lo mismo ha sucedido después que cesó esta planta con tan graves perjuicios del real servicio» ${ }^{67}$.

Parecido discurso aparece bajo la pluma de los Consejeros de Castilla en idénticas fechas. Durante la primavera de 1704, éstos se enfrentaron a menudo con Francisco Ronquillo, Gobernador de Armas en el frente portugués y, por añadidura, buen colaborador de Orry y Canales. Así, cuando Ronquillo secuestró los medios de transporte locales para transportar los víveres del ejército, el gremio de carreteros apeló ante el Consejo de Castilla, quien lo apoyó. La convocación general de los hidalgos y caballeros de Castilla publicada por Ronquillo fue suspendida por el Consejo. En mayo, el Consejo apoyó a Segovia frente a Ronquillo, quien exigía que la ciudad costeara el armamento de milicias. Por fin, en agosto, se indigna al enterarse que Ronquillo publica órdenes contra los desertores distintas de las que el propio tribunal emitión ${ }^{68}$. Si hasta aquí el Consejo de Castilla recurrió a vías indirectas, intentando suspender criaturas de Ronquillo o apoyar las comunidades locales que apelaban contra el gobernardor, ahora, expone sus quejas al rey. Ronquillo, explica, salió del marco de sus competencias

«excediendo los límites de la potestad de sus empleos, empezó a expedir órdenes y publicar bandos ajenos de su instituto y profesión, suponiendo tener orden de Vuestra Majestad, abrogándose ( $\mathrm{sic}$ ) también la autoridad de interpretar la real mente de Vuestra Majestad sin que el Consejo ni los vasallos supiesen para obedecer lo que era del agrado de Vuestra Majestad, siguiéndose de esta ignorancia la disculpa de la inobediencia o en la obediencia mayor perjuicio de la causa pública.»

67. MAE, CPE 139, fol. 70-71, 73, 65-66.

68. AHN, E, leg. 871; BNE, ms 9928, fol. 68-72; Castro: 2004, cap. I-2. 
De este modo, el gobernador de armas se valió de una autoridad «usurpada o concedida»-una posible indirecta para el mismo monarca o para el Secretario del Despacho de Guerra. El procedimiento regular, en cambio, debió ser el siguiente:

«Son los Consejos y tribunales de Vuestra Majestad los medios por donde al logro del mayor servicio se han distribuido siempre las órdenes, siendo en los diversos institutos de cada uno seguro el acierto puntual, la obediencia y venerada la resolución. $)^{(19}$

Idénticos argumentos aparecen bajo otras plumas. En el mismo año 1704, un autor anónimo denuncia la confusión en que se hallan los ejércitos, achacando la situación a la ruptura de las vías ordinarias de resolución de los negocios. Acusa el

«curso irregular de las cosas de palacio y real despacho, es una pura confusión porque se dispone y gobierna todo privadamente por medios indecentes y modos extraordinarios con indecoro y nota, aunque inculpable de la Majestad, huyendo de los tribunales y del curso racional y regular de sus consultas y representaciones. $\rangle^{70}$

En cuanto al duque de Medinaceli, contemplando la situación en las mismas fechas, denuncia: «se ha sacado de su regular quicio el curso de los negocios con el poco aprecio de los tribunales, que era bien enmendarles pero no destruirlos $)^{71}$.

Se impone el sentimiento de ruptura, que todos expresan en términos dramáticos. Ahora bien, esta ruptura nunca se atribuye a la introducción de un estilo francés. Se describe como el recurso a vías extraordinarias de expedición de los negocios, que se quitan a los Consejos, reduciendo de hecho sus competencias, para ser confiados a ministros. Es interesante ver que la interpretación de Ronquillo, partidario y actor de las reformas de 1703-1704, es exactamente simétrica. Como lo escribe al marqués de Canales, el Consejo de Castilla

«lleva muy mal que lo que Su Majestad se sirve mandarme venga en derechura por mano de Vuestra Excelencia y no por aquellos conductos que se quiere hacer precisos siguiendo los estilos de hasta aquí. (...) El Consejo de Castilla tira a arruinar a todos los que han cumplido mis órdenes emanadas de las de Su Majestad que Vuestra Excelencia me ha participado. $\rangle^{72}$

Así, el tribunal intentó destituir a sus protegidos porque habían ejecutado órdenes transmitidos por la nueva vía ${ }^{73}$. Aunque unos y otros valoran la novedad de forma

69. El Consejo de Castilla a Felipe V, 30/08/1704, BNE, ms 9928, fol. 69-72.

70. MAE, CPE 136, fol. 11-13. Traducción mía.

71. Medinaceli a Torcy, 29/02/1704, MAE, CPE 136, fol. 176-178. Traducción mía.

72. Castro: $2004,156$.

73. Sus clientes, como el presidente de la Chancillería de Valladolid, don Juan Manuel de Isla, «se han adquirido buena ojeriza con aquel tan supremo tribunal, porque han ejecutado mis encargos emanados todos de órdenes participadas por Vuestra Excelencia, que no deben de querer los ministros se obedezcan por tales, respecto a la absoluta con que aquella agradable carta del fiscal Pradilla que remití a Vuestra Excelencia le dice al presidente de Valladolid que no debe ejecutar otras que las que fueren firmadas de Su Majestad o por sus tribunales, en cuya cláusula padecemos Vuestra Excelencia y yo y lo que más es el real servicio» (Ronquillo a Canales, 22/04/1704, AHN, E, leg. 871). 
opuesta, positiva o negativamente, todos coinciden en concebirla como una reducción extraordinaria de las competencias de los Consejos.

Ahora bien, la dificultad que se ofrece al investigador es identificar a qué corresponde el «curso racional y regular», el «regular quicio» de los negocios. El carácter reiterativo de los argumentos de sus defensores y su tono categórico («siempre») autorizan a pensar que se trata más de un ideal que de una práctica que habría sido exclusiva antes de 1700. Además, llama la atención el hecho de que algunos de los portavoces de este discurso no son precisamente encarnaciones de la «vía de los Consejos». No olvidemos que Portocarrero fue gobernador de la monarquía en dos ocasiones ${ }^{74}$. En cuanto al manejo del dinero de la flota, él mismo precisa que el rey le concedió facultades extraordinarias, aunque no quiso usar de ellas. Por su parte, Medinaceli, en el pasaje citado, reconoce admitir una reducción de las competencias de los Consejos. En otra ocasión, pocas semanas antes, fue más lejos: consultado por Orry sobre la forma que debería adoptar una junta destinada a paliar la ausencia de reuniones del despacho, en octubre de 1703, propuso que se compusiera de cuatro Grandes responsables de departamentos separados ${ }^{75}$, una solución poco afín al «curso regular». Otra víctima de las reformas, el conde de Monterrey -Presidente del Consejo de Flandes, asistió a su supresión en 1702 - adopta una actitud similar. Consultado por Orry sobre un proyecto de reglamento para los regimientos del rey, la reina y Asturias, empieza afirmando que es preciso consultar al Consejo de Guerra, vía normal en tal materia:

«convendría que Su Majestad le mandase remitir al Consejo pleno de Guerra, porque en materias de estas calidad, por su gravedad e importancia, debe Su Majestad ór los ministros que por su profesión y experiencia tienen obligación a aconsejar lo que más fuere de su real servicio.»

\section{Sin embargo, y aunque el reglamento propuesto}

«es novedad jamás practicada en España ni otros dominios de la monarquía, considera que los ejemplos ajenos suelen hacer olvidar las costumbres propias cuando la experiencia manifiesta el beneficio que resulta de la mudanza.»

Por ello, y para ganar tiempo, él mismo sugiere la vía alternativa que permitirá resolver el asunto sin pasar por el Consejo: el rey puede valerse de la prerrogativa de su regimiento de no depender del Consejo de Guerra. Pedirá a su coronel, Portocarrero, quien se reconoce ignorante en materia militar, que mande examinar el proyecto al teniente coronel ${ }^{76}$.

Defender la vía ordinaria, por lo tanto, no significa excluir la extraordinaria (ya que la primera supone literalmente la segunda), sino conseguir que ésta siga siendo una excepción. Las reflexiones citadas dan la impresión, sin embargo, de que el contenido

74. «Traslado de la orden de Su Majestad [Carlos II] dada al cardenal Portocarrerro, arzobispo de Toledo, sobre encargarle el gobierno de todos sus reinos y de lo militar y económico.», 29/10/1700, AGS, DGT, Inv. 10, leg. 5. Decreto de Felipe V, 01/09/1701, MAE, CPE 93, fol. 34.

75. Orry a Torcy y Chamillart, 05/10/1703, MAE, CPE 120, fol. 124-127; SHAT, A' 1696, n 58.

76. Memorial de Monterrey, 18/09/1703, MAE, CPE 120, fol. 118-120; SHAT, A' 1696, nº 47. 
de lo ordinario cambia de un actor a otro, lo mismo que en la Corona de Aragón, no existe consenso sobre la lista de los fueros a defender ${ }^{77}$. Por lo tanto, la defensa de lo ordinario aparece ante todo como una reivindicación política: la posibilidad de controlar en qué condiciones es lícito recurrir a la vía extraordinaria, sin dejarlo todo al arbitrio del rey o de unos ministros. Convendría preguntarse si en España, este ideal del curso ordinario corresponde a la defensa del equilibrio de poderes relativamente favorable a los Consejos que se observa en la última década del reinado de Carlos II, después de la desaparición de privados y primeros ministros.

De momento, se puede afirmar que para los contemporáneos existen dos lógicas políticas opuestas, la vía de los Consejos y la vía reservada ${ }^{78}$, o la monarquía judicial y la administrativa ${ }^{79}$, pero estas lógicas no corresponden a modelos nacionales. ¿En qué consiste, entonces, el cambio que introducen las reformas políticoadministrativas de los Borbones? Si confiamos en lo que nos dicen los contemporáneos, y en particular las víctimas del cambio, este cambio no consistió tanto en introducir novedades como en sistematizar lo extraordinario, o sea, hacerlo ordinario. El que historiadores del reinado de Luis XIV lleguen a conclusiones similares para Francia contribuye, como lo sugirió Guillamón Álvarez, a diluir la noción de modelos nacionales opuestos ${ }^{810}$.

\section{CONTEXTUALIZAR: MIRADAS RECÍPROCAS}

Al mismo tiempo, las afinidades entre Francia y España sugieren otras pistas de investigación susceptibles de enriquecer el análisis. Me contentaré con señalarlas.

Es interesante conocer el «curso ordinario» francés o la «confusión» con la que acabó Luis XIV. La posibilidad de que las dinámicas de cambio que conocieron Francia y España no sean tan disímiles, el hecho, por lo menos, de que los contemporáneos las interpretan de forma similar, compartiendo un mismo vocabulario político y una representación común de las formas de gobierno que se enfrentan en cada país, se pueden verificar examinando el discurso de los franceses hostiles a las reformas de Luis XIV. Los estudios de los argumentos antiabsolutistas de Saint-Simon, Fénelon o, en el círculo íntimo del rey Sol, los duques de Chevreuse y Beauvillier ${ }^{81}$, revelan así similitudes entre el discurso de estos franceses y el de los defensores del curso ordinario en España citados arriba. Asimismo, en su Discours sur la polysynodie publicado en 1719, el abad Saint-Pierre justifica de forma idéntica el gobierno colegial instituido en Francia por el regente ${ }^{82}$. Además, los reparos a que responde se hacen eco de los argumentos de

77. Giménez López: 1999, 13-47; Gil Pujol: 2002.

78. Quien habla de vía de los Consejos es Castro: 2004. Se sabe que los contemporáneos ya hablaban de vía reservada a finales del siglo XVII (Dedieu: 2000a; López Cordón: 2000).

79. Fernández Albaladejo: 1993, 406-409; Giménez López: 1999, 13-47.

80. Ver la síntesis de Chaline: 2005 (en particular p. 312).

81. Ver la sintesis de Chaline: $2005,577-578$ y 704-709, así como su bibliografía; Petitfils: 2002, 533 y sigs.

82. En particular, el rey estaría mejor informado por varios consejeros iguales entre sí, y de opiniones contradictorias, que por un solo «vizir» propenso a seleccionar la información que le beneficiaría; las decisio- 
los promotores de la vía reservada en España ${ }^{83}$. Resultaría útil una comparación más precisa de los discursos desarrollados en ambas vertientes de los Pirineos. Pero aquí también, merecería ser completada por el estudio de la visión que los franceses favorables al gobierno colegial tienen de España. Así, aunque algunos historiadores franceses señalan como una evidencia que el modelo de la regencia en 1715 fue español ${ }^{84}$, que yo sepa, no se estudiaron las eventuales referencias de los promotores de esta reforma en Francia a la práctica de gobierno española.

Por otra parte, afirmar que no existen dos modelos nacionales unívocos, uno francés y el otro español, y que en cambio franceses y españoles parecen compartir una misma cultura política a principios del siglo XVIII obliga a abrir la perspectiva. En efecto, es deseable definir los límites de un espacio de cultura política común que podría ser más amplio. Resulta esclarecedor, al respecto, fijarse en el gobierno de los Habsburgos de Austria. Ya en los años 1970, Jean Bérenger demostró que Leopoldo ${ }^{\circ}$ decidió, al principio de su reinado (1657-1705), «gobernar por sí solo», como su primo de Francia, precisaba el historiador. Esto suscitó debates entre los partidarios de un gobierno «ministerial» y los del gobierno «colegial» similares a los de España o Francia $^{85}$. Las investigaciones de Virginia León Sanz sobre las instituciones y prácticas de gobierno del rival de Felipe V, Carlos III, en la corona de Aragón primero y en el imperio posteriormente, confirman cierta orientación absolutista de los Habsburgos austríacos e invitan a superar visiones simplistas de los modelos. En efecto, la historiadora demuestra que aunque el pretendiente asienta su legitimidad en el respeto a los privilegios y reglas instauradas por los Habsburgos españoles, su práctica de gobierno se parece en muchos aspectos a la de Felipe V: el protagonismo concedido a su Secretario de Estado y del Despacho o la creación, en el reino de Valencia, de un «Consejo de Gabinete similar al Consejo del despacho felipista» justifican el paralelo. Es un gobierno, por lo tanto, «ambiguamente tradicionalista», según la autora ${ }^{\$ 6}$. En efecto, aquí, como en la España fiel al Borbón, la tradición adquiere un contenido flexible, con fuerte carga retórica, confirmando que sería imprudente adoptar una

nes serian mejor examinadas por muchos que por uno; los consejeros, obligados a expresarse en presencia de sus colegas, no se dejarían guiar por el interés privado sino por el bien público; bien formados en leyes, podrían elaborar los reglamentos necesarios; el control recíproco y el de los sucesores en un cargo limitarían el fraude. Así, el rey evitaría cometer injusticias involuntarias, recaudar impuestos excesivos, etc. Por otra parte, tal gobierno sería estable, mientras el de un solo ministro depende de la calidad, del humor y de la salud de un único hombre, y por lo tanto sufre variaciones importantes. Saint-Pierre: 1719 , en part. $26-29,39-41$.

83. El gobierno colegial hace imposible conservar secretos de Estado; la ejecución de las decisiones sufre retrasos por la lentitud del examen de los expedientes y por los conflictos de competencias entre Consejos; en ausencia del rey, que no asiste a todos los Consejos, se desarrollan la corrupción y el vicio, como sucedió en España durante el siglo que siguió al reinado de Felipe II. Saint-Pierre: 1719, $2^{\mathrm{a}}$ parte.

84. El propio Saint-Pierre no se refiere en ningún momento a España, salvo cuando cita los argumentos de sus adversarios (cfi. n. supra).

85. Bérenger: 1975.

86. León Sanz: 2000, 49-50, 57. 
visión estática del «curso ordinario». Por fin, un partidario de Carlos III y el gobierno tradicional, Juan Amor de Soria, elabora en 1714 un proyecto de división del Despacho en cuatro Secretarías. Comentándolo, León Sanz remite a tres modelos: además de la Francia absolutista, el reformismo de Felipe V, pero también la administración española anterior a $1700^{87}$. No se trata ya de saber qué monarca tuvo la primacía de las reformas $^{88}$. La misma dificultad de identificar un modelo nacional exclusivo nos obliga a salir de este marco para reflexionar en términos de cultura política común.

\section{ABREVIATURAS}

AHN: Archivo Histórico Nacional (Madrid)

E: Estado

BNE: Biblioteca Nacional de España (Madrid)

BNF: Bibliothèque Nationale de France (París)

MAE: Ministère des Affaires Etrangères (París)

CPE: Correspondance Politique Espagne (sigue el núm. de caja)

SHAT: Service Historique de l'Armée de Terre (Vincennes)

$\mathrm{A}^{\prime}$ : Serie de correspondencia antigua (sigue el núm. de libro)

\section{BIBLIOGRAFÍA}

\section{Fuentes publicadas}

Baviera (Príncipe Adalberto de) y MaURa Gamazo (Gabriel): 1935, Documentos inéditos referentes a las postrimerías de la Casa de Austria en España, t. V (1699-1703), Madrid, Tipografía de Archivos.

COLBERT: 1863-1873, Lettres, instructions et mémoires de Colbert. Publiés d'après les ordres de l'empereur, sur la proposition de Son Excellence M. Magne, Ministre secrétaire d'État des Finances, par Pierre Clément, membre de l'Institut, París, Imprimerie Impériale.

LÉONARDON (H.) y MOREL-FATIO (A.): 1898, Recueil des instructions données aux ambassadeurs et ministres de France, depuis les traités de Westphalie jusqu'à la Révolution Française, Publié sous les auspices de la commission des archives diplomatiques du ministère des Affaires Etrangères. Tome XII: Espagne. Avec une introduction et des notes par (...). Tome deuxième (1701-1722). París, Félix Alcan.Luis XIV: 1978, Mémoires, ed. Jean Longnon, París, Librairie Jules Tallandier.

PORTUGUÉS (Joseph Antonio): 1764, Colección general de las ordenanzas militares, sus innovaciones y aditamentos, dispuesta en diez tomos, con separación de clases, por don Joseph Antonio Portugués, Caballero del orden de Santiago, Cornendador de Villarubia de los

87. «Aunque el modelo de referencia fuera la administración absolutista francesa, la propuesta aparece cercana al reformismo administrativo español del Setecientos y recuerda el proceso iniciado con la reorganización ministerial de 1714 , un proceso que tenía sus raíces en la propia evolución de la administración española precedente.» (León Sanz: 2000, 57-58)

88. En olra obra, la misma historiadora se refiere a «reformas 'a la europea'» (León Sanz: 1993, 86). 
Ojos en la de Calatrava, del Consejo de SM y su Secretario, con ejercicio en la primera Mesa de la Secretaría de Estado,y del Despacho universal de la Guerra, Madrid, Imprenta de Antonio Marín.

SAint-Pierre (abbé de): 1719, Discours sur la Polysynodie, où l'on démontre que la Polysynodie ou pluralité des Conseils est la forme de Ministère la plus avaniageuse pour un Roi et pour son Royaume, par M. (...) ci-devant de l'Académie Françoise, Amsterdam, Du Villard et Changuion.

SAINT-SimON (duc de): 1879, Mémoires de Saint-Simon. Nouvelle édition collationnée sur le manuscrit autographe, augmentée des additions de Saint-Simon au Journal de Dangeau, ed. de A. de Boislile, París, Hachette.

VILLARS (marquis de): 1893, Mémoires de la cour d'Espagne de 1679 à 1681 [redactado entre 1685 y 1689$]$, ed. A. Morel-Fatio, París, Plon.

\section{Estudios}

ABBAD (Fabrice) y OzANAM (Didier): 1992, Les intendants espagnols du XVIlle siècle, Madrid, Casa de Velázquez.

Alamo MARTEll (María Dolores): 1997, «'Racionalización impositiva’: una aproximación a las medidas hacendísticas de Jean Orry en la guerra de Sucesión española.», Revista de ciencias juridicas, $\mathrm{n}^{\circ} 3$, pp. 13-28.

Álvarez López (Ana): 1999, El viaje de España. Papel de los viajeros franceses por España en la formación del estereotipo de lo español (s. XVI-XVIII), Alcalá de Henares, Universidad de Alcalá de Henares.

ANDRÉS UCENDO (José Ignacio): en prensa, «L'embryon d'une nouvelle administration fiscale: les administrateurs en Castille dans la seconde moitié du XVIle siècle» en Anne Dubet ed., Administrer les finances royales dans la monarchie espagnole (XVIe-XIXe siècles), Clermont-Ferrand, Presses Universitaires de Clermont-Ferrand, cap. 8.

Andújar CAStillo (Francisco): 1996, Consejo y Consejeros de Guerra en el siglo XVIII, Grenade, Universidad de Granada.

ANDÚJAR CASTILlo (Francisco): 2000, «La reforma militar en el reinado de Felipe V», José Fernández García, María Antonia Bel Bravo, José Miguel Delgado Barrado, El cambio dinástico y sus repercusiones en la España del siglo XVII, Jaén, Universidad de Jaén, pp. 617-640.

ANdÚJar CAStILlo (Francisco): 2004, El sonido del dinero. Monarquia, ejército y venalidad en la España del siglo XVIII, Madrid, Marcial Pons Historia.

Andúuar Castillo (Francisco): en prensa, Tiempo de necesidad, tiempo de venalidad. España e Indias, $1705-1711$.

ANTONE (Michel): 2003, Le cour de l'État. Surintendance, contrôle général et intendances des finances, 1551-1791, París, Fayard.

Baltar Rodriguez (Juan Francisco): 1998, Las Juntas de Gobierno en la Monarquía Hispánica, Madrid, Centro de Estudios Políticos y Constitucionales.

BaudrillarT (Alfred): 1890, Philippe V et la cour de France. D'après les documents inédits tirés des archives espagnoles de Simancas et d'Alcalá de Henarès et des archives du mi- 
nistère des affaires étrangères à Paris, París, Librairie de Firmin-Didot et Compagnie, 5 tomos.

Bérenger (Jean): 1975, Finances et absolutisme autrichien dans la seconde moitié du XVIle siècle, París, Université de Paris IV Paris-Sorbonne, Publications de la Sorbonne.

CÁRCELES DE GEA (Beatriz): 1993, La Comisión de Millones (1632-1658): Poder fiscal y privilegio juridico-político, Madrid, Banco de España.

CÁrCeles de GeA (Beatriz): 2000, Fraude y desobediencia fiscal en la corona de Castilla (1621-1700), Madrid, Junta de Castilla y León.

CASTELlANo (Juan Luis) ed.: 1996, Sociedad, administración y poder en la España del Antigno Régimen. Hacia una nueva historia institucional. I Simposium internacional del grupo PAPE (Granada, septiembre de 1994), Granada, Universidad de Granada.

CASTEllano (Juan Luis) y Dedieu (Jean-Pierre): 1998, Réseaux, familles et pouvoirs dans le monde ibérique à la fin de l'Ancien Régime, París, CNRS.

CASTELLANO (Juan Luis): 2002, «El gobierno en los primeros años del reinado de Felipe V. La influencia francesa) en José Luis Pereira Iglesias coord., Felipe V de Borbón, 1701-1746. Actas del congreso de San Fernando (Cádiz) de 27 de noviembre a I de diciembre de 2000, Córdoba, Universidad de Córdoba, pp. 131-142.

CASTro (Concepción de): 2000, «El Estado español en el siglo XVIII: su configuración durante los primeros años del reinado de Felipe V», Historia y política. Ldeas, procesos y movimientos sociales, $\mathrm{n}^{\circ} 4$, pp. 137-169.

CASTRO (Concepción de): 2004, A la sombra de Felipe V. José de Grimaldo, ministro responsable (1703-1726), Madrid, Marcial Pons Historia.

Chaline (Olivier): 2005, Le règne de Louis XIV, París, Flammarion.

Claro Delgado (Manuel): 2001, «La Guerra de Sucesión española y la creación de un nuevo ejército», La Guerra de Sucesión en España y América. Actas X Jornadas Nacionales de Historia Militar: Sevilla, 13-17 de noviembre de 2000, Madrid, Deimos, pp. 495-539.

CoRnetTe (Joël): 1996, «La tente de Darius» en Joël Comette y Henry Méchoulan ed. L'Elat classique 1652-1715, París, Vrin, pp. 9-41.

CORNETTE (Joël), 2000a, Le roi de guerre. Essai sur la souveraineté dans la France du Grand Siècle, París, Petite Bibliothèque Payot ( $1^{\text {a }}$ ed.: 1993).

CORNetTE (Joë1): 2000b, Histoire de la France: Absolutisme el Lumières, 1652-1783, París, Hachette.

DEDiEu (Jean-Pierre) y Ruiz RoDríGuez (José Ignacio): 1994, «Tres momentos en la historia de la Real Hacienda", Cuadernos de Historia Moderna, ${ }^{\circ}$ 15, pp. 77-98.

DEDiEu (Jean-Pierre): 2000, «La Nueva Planta en su contexto. Las reformas del aparato del Estado en el reinado de Felipe V», Manuscrits, 18, pp. 113-139.

Dedieu (Jean-Pierre): 2002, «Dinastía y élites de poder en el reinado de Felipe V» en Pablo Fernández Albaladejo ed., Los Borbones. Dinastía y memoria de nación en la España del siglo XVIII, Madrid, Marcial Pons Historia, Casa de Velázquez, pp. 381 -399.

DEsserT (Daniel): 2000, Colbert ou le serpent venimeux, París, Complexes. 
DUBET (Anne): 2005, «Administrar los gastos de la guerra: Juan Orry y las primeras reformas de Felipe V (1703-1705)» en Agustín Guimerá y Víctor Peralta (coord.), El Equilibrio de los Imperios: De Utrecht a Trafalgar. Actas de la VIII Reunión Cientifica de la Fundación Española de Historia Moderna (Madrid, 2-4 de junio de 2004), Madrid, Fundación Española de Historia Moderna, Consejo Superior de Investigaciones Cientificas, Universidad Complutense, Sociedad Estatal de Conmemoraciones Culturales, pp. 483-501.

DUBET (Anne): 2006, «L'autorité royale et ses limites: les projets de Jean Orry pour l'administration des finances espagnole au début du XVIIIe sièclè en Jean-Philippe Luis, Luis Martín y Natividad Planas eds., Institutions et représentations politiques en Europe méridionale (XVIJe-XXe siècles), Clermont-Ferrand, Presses Universitaires Blaise Pascal, pp. $81-96$.

DUBET (Anne): en prensa (I), Jean Orry et le gouvernement de l'Espagne (1701-1706), Clermont-Ferrand, Presses Universitaires Blaise Pascal.

DUBET (Anne): en prensa (II), «La creación del Tesorero Mayor de Guerra (1703-1715), instrumento de una nueva política de crédito al rey», LXIV Congreso Internacional de Historia Económica - Helsinki (agosto de 2006), sesión Government debts and financial markets in Europe, 16th-20th Centuries, coordinada por José Ignacio Andrés Ucendo, Pierre-Cyrille Hautcoeur, Michael North, Fausto Piola Caselli (agosto de 2006).

EMmANuelli (François-Xavier): 1981, Un mythe de l'absolutisme bourbonien: l'intendance, du milieu du XVIIe siècle à la fin du XVIIIe siècle (France, Espagne, Amérique), Aix-enProvence, Université de Provence.

Escudero (José Antonio): 1969, Los secretarios de Estado y del Despacho (1474-1724), Madrid, Instituto de Estudios administrativos.

Escudero (José Antonio): 1979, Los origenes del Consejo de Ministros en España. La junta suprema de Estado, Madrid, Editora Nacional.

ESCUDERO (José Antonio): 1985, «La reconstrucción de la administración central en el siglo XVIIl» dans Historia de España Menéndez Pidal. La época de los primeros Borbones, Madrid, Espasa-Calpe, t. XXIX *, chap. I-IV.

Fernández Albaladejo (Pablo): 1993, Fragmentos de Monarquía, Madrid, Alianza Universidad.

Franco Rubio (Gloria A.): 1996, «La secretaría de Estado y del Despacho de Guerra en la primera mitad del siglo XVIII» en Castellano ed.: 1996, pp. 131-156.

Franco Rubio (Gloria), López-Cordón CorTEzo (María Victoria), Nava Rodríguez (Teresa): 1996, «Perfiles socioprofesionales de la burocracia española en el s. XVIII: las Secretarías de Estado y del Despacho» en Luis Miguel Enciso Recio, La burguesia española en la Edad Moderna, pp. 1009-1034.

GaChard (Louis-Prosper): 1867, La Belgique sous Philippe V, Bruselas, Fr. Gobbaerts.

Garzón PAREja (Manuel): 1981, La hacienda de Carlos II, Madrid, Instituto de Estudios Fiscales.

Gil Pujol (Xavier): 2002, «La corona de Aragón a finales del siglo XVII: a vueltas con el neoforalismo» en Pablo Fernández Albaladejo ed., Los Borbones. Dinastía y memoria de- 
nación en la España del siglo XVIII, Madrid, Marcial Pons Historia, Casa de Velázquez, pp. 97-115.

GIMÉNEz LÓpez (Enrique): 1999, Gobernar con una misma ley. Sobre la Nueva Planta borbónica en Valencia, Alicante, Universidad de Alicante.

GONZÁLEZ FuerTES (Manolo Amador): 2002, La organización institucional de la Cámara de Castilla en la época borbónica, Córdoba, Universidad de Córdoba.

Guillamón Álvarez (Francisco Javier): 2000, «EI cambio dinástico y sus repercusiones en la España del siglo XVIIl» en José Fernández García, María Antonia Bel Bravo, José Miguel Delgado Barrado ed., El cambio dinástico y sus repercusiones en la España del siglo XVII, Jaén, Universidad de Jaén, pp. 529-542.

HESPANHA (Antonio Miguel): 1992, «La «Restauração» portuguesa en los capítulos de las Cortes de Lisboa de $1641 »$ en John H. Elliott, Roberto Villari, Antonio Miguel Hespanha, Bruno Anatra «y otros», 1640: la Monarquía hispánica en crisis, Barcelona, Crítica, pp. 123 168.

IBÁ̃̃ez MOLina (Manuel), 1982, «Notas sobre la introducción de los intendentes en España», Anuario de Historia Contemporánea, $\mathrm{n}^{\circ}$ 9, pp. 5-27.

KAMEN (Henry): 1964, «El establecimiento de los intendentes en la administración española», Hispania, XXIV, pp. 368-395.

KAMEN (Henry): 1974, La Guerra de Sucesión en España, 1710-1715, Barcelona, Buenos Aires, México D.F., Grijalbo.

La Guerra de Sucesión en España y América. Actas X Jornadas Nacionales de Historia Militar. Sevilla, 13-17 de noviembre de 2000, Madrid, Deimos, 2001

LEÓN SANZ (Virginia): 1993, Entre Austrias y Borbones. El Archiduque Carlos y la monarquía de España (1700-1714), Madrid, Sigilo.

LEÓN SANZ (Virginia): 2000, «EI reinado del archiduque Carlos en España: la continuidad de un programa dinástico de gobierno», Manuscrits, 18, pp. 41-62.

LÓPEZ CORDÓN CORTEZO (María Victoria): 1996a, «Secretarios y secretarías en la Edad Moderna: de las manos del príncipe a relojeros de la monarquía), Studia Historica. Historia moderna, 15, pp. 107-131.

LÓPEZ CORDÓN CORTEZO (María Victoria): 1996b, «Cambio social y poder administrativo en la España del siglo XVIII: las secretarías de Estado y del Despacho» en Castellano ed: 1996, pp. $113-130$.

LÓPEZ CORdón CORTEZo (María Victoria): 1996c, «Oficiales y caballeros: la carrera administrativa en la España del siglo XVIII» en El mundo hispánico en el siglo de las Luces, Madrid, Sociedad Española de Estudios del siglo XVIII - Fundación Duques de Soria - Editorial Complutense, t. II, pp. 843-853.

LÓPEZ CORDÓN CORTEZO (María Victoria): 2000, «Instauración dinástica y reformismo administrativo: la implantación del sistema ministerial», Manuscrits, 18, 2000, pp. 93-111.

LÓPEZ CORDÓN CORTEZO (María Victoria): 2004, «Burocracia y erudición en la España del siglo XVIIl $\gg$ en Jean-Pierre Dedieu y Bernard Vincent ed., L'Espagne, l'État, les Lumières. Mélanges en l'honneur de Didier Ozanam, Madrid, Casa de Velázquez, pp. 155-171. 
MADRAZO (Santos): 2000, Estado débil y ladrones poderosos en la España del siglo XVIII. Historia de un peculado en el reinado de Felipe $V$, Madrid, Catarata.

MuÑoz RodrígueZ (Julio D.) y RuIZ IBÁÑEz (José Javier): 2002, «Sirviendo a la corte en la aldea, sirviendo a la aldea en la corte: veteranos, agentes y medios de relación en el siglo XVII castellano» en Jesús Bravo Lozano ed., Espacios de poder: Cortes, Ciudades y Villas (s. XVI-XVII), Madrid, Universidad Autónoma de Madrid, 2002, vol. II, pp. 227-247.

MuÑoz Rodríguez (Julio D.): 2003, «Consenso e imposición en la conservación de la monarquía. La práctica política de un territorio de la periferia castellana: el reino de Murcia (1682-1700)», Hispania, LXIII/3, n² 215, 2003, pp. 969-994.

MUÑOZ Rodríguez (Julio D.): 2004, «Cuando el rey se hace presente. El Superintendente como elemento racionalizador en la recaudación fiscal castellana» en Francisco José Aranda Pérez dir., La declinación de la monarquía Hispánica en el siglo XVII. Actas de la VIIa Reunión Cientifica de la Fundación Española de Historia Moderna (Ciudad Real, 3, 4, 5 y 6 de junio del año 2002), Cuenca, Universidad de Castilla-La Mancha, pp. 377-390.

NAVA Rodríguez (Teresa): 1996, «La secretaría de Hacienda en el Setecientos español: una aproximación prosopográfica», El mundo hispánico en el siglo de las Luces, Sociedad Española de Estudios del siglo XVIII - Fundación Duques de Soria - Editorial Complutense, Madrid, t. II, pp. 948-966.

NAVA RODRÍGuez (Teresa): 2004, «Nervios de bóveda': las tesorerías centrales de la hacienda borbónica (1716-1743)» en Enrique Martínez Ruiz coord., III seminario hispanovenezolano. Vinculos y sociabilidades en España et Iberoamérica. Siglos XVI-XX, Ciudad Real, pp. $111-131$.

OZANAM (Didier): 1995, «La restauration de l'État espagnol au début du règne de Philippe V (1700-1724): le problème des hommes» en Philippe $V$ d'Espagne et l'Art de son temps. Actes du colloque des 7, 8 et 9 juin 1993 à Sceaux sous la haute autorité scientifique du Professeur Yves Bottineau, París, Musées de l'Ile de France, vol. 2, pp. 79-89.

OZANAM (Didier): 1997, «Les intendants espagnols de la première moitié du XVIIIe siècle, 1711-1749》 en Robert Descimon, Jean-Frédéric Schaub y Bernard Vincent ed., Les figures de l'administrateur. Institutions, réseaux, pouvoirs en Espagne, en France et au Portugal, $16^{c}$-19' siècle, París, Editions de l'EHESS, pp. 181-199.

PABlo CANTERo (Antonio de): 2001, «La infantería de Felipe V, 1700-1718», La Guerra de Sucesión en España y América. Actas X Jornadas Nacionales de Historia Militar. Sevilla, 13-17 de noviembre de 2000, Madrid, 2001, pp. 384-397.

PARejo Delgado (María Josefa): 2001, «Las ordenanzas militares durante la Guerra de Sucesión», La Guerra de Sucesión en España y América. Actas X Jornadas Nacionales de Historia Militar: Sevilla, 13-17 de noviembre de 2000, Madrid, 2001, pp. 461-480.

Petitfils (Jean-Christian): 2002, Louis XIV, París, Librairie Perrin ( ${ }^{a}$ ed.: 1995).

PEYTAVIN (Mireille): 1998, «Españoles e italianos en Sicilia, Nápoles y Milán durante los siglos XVI y XVII: sobre la oportunidad de ser «nacional» o «natural»» en La Monarquía española: grupos politicos locales ante la corte de Madrid, Relaciones, $\mathrm{n}^{\circ} 73$, pp. 85-114.

Ribot García (Luis Antonio): 1993, «La España de Carlos Il», Historia de España Menéndez Pidal. XXVIII. La transición del siglo XVII al XVIII, Madrid, Espasa-Calpe, pp. 63-203. 
RUIZ JIMÉNEZ (Marta): 2000, «La monarquía borbónica francesa del siglo XVIII: un modelo en crisis», Manuscrits, 18, pp. 23-28.

SÁNCHEZ BELÉN (Juan Antonio): 1996, La politica fiscal en Castilla durante el reinado de Carlos $I I$, Madrid, Siglo XXI.

SChaub (Jean-Frédéric): 2001, Le Portugal au temps du Comte-Duc d'Olivares (1621-1640). Le conflit de juridictions comme exercice de la politique, Madrid, Casa de Velázquez.

SCHAUB (Jean-Frédéric): 2003, La France espagnole. Les racines hispaniques de l'absolutisme français, París, L'Univers Historique, Seuil (hay versión española).

SMEDLEY-WEILL (Anette): 1995, Les intendants de Louis XIV, Paris, Fayard. 